\title{
DESCRIPTION OF THE COMPOUND STEAM TURBINE AND TURBO-ELECTRIC GENERATOR.
}

By the Honourable Charles A. Parsons, of Gateshead.

The Compound Steam Turbine has now been developed into a mator which utilizes steam with a high degree of economy. It possesses considerable simplicity, and its speed of revolution is high; and as dynamos working at a high speed combine cheapness and efficieney, the application of the steam turbine for driving them is at first sight a good one. The combination of the steam turbine and dynamo has involved a considerable departure from existing practice, and has necessitated much experimental work, and investigations on entirely new ground.

The first Turbo-Electric Generator, completed about four years ago, ran at 18,000 revolutions per minute, and gave six electrical horse-power; it has been in almost constant use since that time, and has done a large amount of work. The second, made shortly afterwards, runs at 10,000 revolutions per minute; it was placed on the Tyne Steam Shipping Co.'s steamer "Earl Percy," and has worked her 60 lamps ever since to their entire satisfaction; the cost of fuel and maintenance is very small, and the light remarkably steady. Generators were then made for supplying up to 250 lamps, and a large number of installations were carried out, which have given excellent results; the consumption of steam was about equal to that of a good high-pressure engine with single slide when working with the same steam pressure and driving a good dynamo; but so marked has been the economy realised in regard to Iamp renewals, oil, attendance, and other items, that the generators have almost without exception given great satisfaction. It became essential however, if these generators were to be successfully adopted for large installations, that higher degrees of economy should be realised, more nearly approaching those of the best compound engines. Theory based on the authenticated performances of 
water turbines and the laws of the flow of steam and gases showed that the turbo-electric generator possessed the elements of the highest economy, not merely comparable with the best known performances, but even superior to them. How far practice has come up to theory may be judged by the results given at the end of this paper, which it will be seen approach nearly the best results of ordinary engines working with the same steam pressures.

Compound Steam Turbine.-The compound steam turbine T, Figs. 1 and 2, Plates 85 and 86, consists of two series of parallel-flow or Jonval turbines, set one after the other on the same spindle $S$, so that each turbine takes steam from the one before and passes it on to the one following. In this way the steam entering all round the spindle from the central inlet I, Fig. 1, passes right and left through the whole of each series of turbines to the exhaust $\mathbf{E}$ at each end. The steam expands as it loses pressure at each turbine; and by successive steps the turbines are increased in size or area of passage-way, so as to accommodate the increase of volume, and to maintain a suitable distribution of pressure and velocity throughout the whole series of turbines. The areas of the successive turbines are so arranged that the velocity of the flow of steam shall bear throughout the series about the same ratio to the speed of the blades; and as far as possible this ratio of velocity is so fixed as to give each turbine of the series its maximum efficiency. The two equal series of turbines on each side of the central steam inlet I balance each other as regards any end pressure on the spindle of the motor, and thus remove any tendency to undue wear on the collars of the bearings $\mathbf{B}$.

The turbines are constructed of alternate revolving and stationary rings of blades. The revolving blades r, Fig. 9, Plate 90, are cut with right or left-hand obliquity on the outside of a series of brass rings, which are threaded upon the horizontal : steel driving spindle $B$, and secured upon it by feathers; the end rings form nuts, which are screwed upon the spindle and hold the rest of the rings upon it. The stationary or guide blades $g$ are cut with opposite obliquity on the inside of another series of larger brass rings, which are cut in halves, and are held in the top and bottom halves of the 
cylindrical casing by feathers. The set of blades on each revolving ring runs between a pair of sets of the stationary or guide blades. The passages between the blades in the alternating rings form a longitudinal series of zigzag channels when the machine is standing still, as seen at $Z$ in Plates 86 and 90.

Bearings.-In Fig. 6, Plate 87, is shown full size a longitudinal section of one of the bearings. As it is impossible to secure absolute accuracy of balance, the bearings are of special construction so as to allow of a certain very small amount of lateral freedom. For this purpose the bearing is surrounded by two sets of steel washers 1-16th inch thick and of different diameters, the larger fitting close in the casing $\mathbf{C}$ and about 1-32nd inch clear of the bearing, and the smaller fitting close on the bearing and about 1-32nd inch clear of the casing C. These are arranged alternately, and are pressed together by the spiral spring N. Consequently any lateral movement of the bearing causes them to slide mutually against one another, and by their friction to check or damp any vibrations that may be set up in the spindle. The tendency of the spindle is then to rotate about its axis of mass, or principal axis as it is called; and the bearings are thereby relieved from excessive pressure, and the machine from undue vibration. The automatic oiling of the bearings by the screw $J$, Plate 86 , almost entirely prevents friction and wear. The circulation is continuous, the oil being used over and over again; and as it deteriorates very slowly, and there is little waste, the consumption may be said to be unusually small. The oil is raised $u p$ to the serew $J$ by the suction of the fan $F$ acting upon its free surface in the stand-pipe $P$. By the screw $J$ it is fed into the adjoining bearing, and is also forced along the pipe $\mathrm{H}$ to the two other bearings of the spindle. After passing through the bearings the oil flows back along the pipe $K$ to the reservoir W, Plate 85 , to be again drawn up thence through the pipe $U$ by the fan and fed into the bearings by the screw. The throttle-valve $\mathrm{V}$ is worked by the movement of a leather diaphragm $\mathrm{L}$, which the suction of the fan $F$ tends to close against the tension of the spring $A$. 
Turbo-Electric Generator.-In Plates 85 and 86 is represented a turbo generator of 25 horse-power actual. All the turbines are here of the same diameter, and the expansive action of the steam is utilized by varying the depth and pitch of the.blades.

In Plates 88 to 90 is shown a 50 horse-power turbo generator, which may be said to be of the triple-expansion type, from the fact that it is made with three different diameters of turbines for the purpose of dealing more advantageously with the increasing volume of steam as it expands. The three barrels $H K M$ of different diameters, Plate 89 , contain the three successive sizes of turbines. In each barrel the blades are continuously varied in pitch, so that an almost perfect distribution of steam is attained; and each barrel by itself may be compared in some respects with a cylinder in a triple compound engine. In the larger sizes the blades are accurately curved, as shown at Z, Plate 90 , as in the best water turbines. To prevent end pressure, the spaces at the ends of the corresponding barrels are connected by equalizing passages $Q$, Plate 89.

Including fluid friction, the theoretical effciency of each turbine in the set is about 89 per cent.; and the mean efficiency of the whole set is theoretically about 87 per cent. of the power which should be given out in the adiabatic expansion of the steam. At each turbine the flow of steam is continuous, and proceeds unchecked to the next. The steam expands slightly in passing each set of blades, but without shock and with gradually diminishing pressure, the whole energy of expansion being utilized to carry the steam through the subsequent turbines.

With the continuous lubrication and small pressure on the bearings, there is no material wear; and as the steam has no cutting action on the turbines, the initial clearances remain the same. Therefore the consumption of steam in the turbo motor does not increase under the conditions of every day running, and after long periods of work has been found to remain almost the same as on the trial run. The power absorbed in friction in the bearings has been estimated : when they are cold it is considerable, amounting to over one-third of a horse-power per bearing; but when the oil 
becomes heated to its normal temperature, it falls to less than twenty per cent. of this amount.

Dynamo.-The motor is coupled to the dynamo D, Plates 85 and 88, by a coupling socket with squared hole J, Figs. 8 and 9, which fits accurately upon the squared ends of the two spindles; this admits of the armature being easily withdrawn. The magnets are entirely of cast-iron, and usually are made with simple shuntwinding only.

The armature, Fig. 5, Plate 87, is of the drum type. The body is built up of thin iron discs, only 1-100th of an inch thick and insulated from each other by tracing paper; it is turned up, and grooves are milled out to receive the conducting wires. For pressures of from 60 to 80 volts, there are usually thirty grooves. The course of the wire is as follows :- starting at $\omega$ it is led spirally through a quarter of a turn $b$ round the cylindrical portion $c$; then passing longitudinally along a groove in the core it is again led spirally through a quarter turn $d$ round the other cylindrical portion $c$, then through the end washer, and then back similarly through a quarter spiral turn $e$, and along the diametrically opposite groove in the core, and lastly through a little more than a quarter spiral $\operatorname{turn} f$, back to $g$, where it is coupled to the next convolution.

The commutator is formed of rings of sections. Each section is formed of short lengths, and each length is dovetriled and interlocked between conical steel rings; the whole is insulated with asbestos, and when screwed up by the end nut forms with the steel bush a compact whole. There are fifteen sections in the commutator, and each coupling is connected to a section. The whole armature is bonnd entirely from end to end with pianoforte or brass wire.

Efficiency of Dynamo.-For a normal output of 400 ampères and 80 volts, the resistance of the armature from brush to brush is only $0.0025 \mathrm{ohm}$. The resistance of the field magnets is $23 \mathrm{ohms}$, or an electrical efficiency of just 98 per cent. There are losses due to eddy currents in the core and wire of the armature, and to magnetio retardation resulting from change of polarity of the core. These 
losses have been ascertained by separately exciting the magnets from another dynamo, and observing the change of steam pressure required to maintain the speed constant; the corresponding power was then calculated. The commercial efficiency of this dynamo has been found to be about 95 per cent.

Electrical Control Governor.-On the magnet yoke is the electrical control governor G, Plates 85 and 88 , shown one quarter full size in Figs. 3 and 4, Plate 87, the movement of which is caused by the attraction of the magnet yoke upon a small iron bar or needle n, finely balanced and pivoted on a vertical spindle; a spiral spring 8 resists this attraction. A double finger or arm $r$ is keyed on the same vertical spindle; the ond of each finger $r$ is flat, and when opposite the inlet $i$ to the air-pipe $Y$ closes it. The spiral spring 8 is so adjusted by the movable head $h$ that the greater the attzaction the more is the inlet $i$ closed by one of the fingers $r$. When the inlet $i$ is open, the inrush of air along the pipe $Y$ partially nentralizes the suction of the fan $F$, and allows the diaphragm $L$ to extend, and so to open the throttle-valve $V$. The combination of the fan $F$, the diaphragm $L$, and the spring $A$, forms a good centrifagal governor; but alone it is not accurate enough in its action for electrical purposes, and requires supplementing by the delicate control of the finely balanced and piroted magnetic needle $n$. So accurate is the governor with this addition, that, when the load is gradually varied from nothing up to the maximum, the variation in volts at the terminal is less than one per cent.

Steam Consumption.-As the result of careful tests made when exhausting into the atmosphere and giving off 32,000 watts, the consumption of steam per electrical horse power per hour has been found to be $42 \mathrm{lbs}$. with a steam pressure of $61 \mathrm{lbs}$. at the inlet; and $35 \cdot 1$ lbs. with a steam pressure of 92 lbs. at the inlet. 'Tests made at Portsmouth Dockyard, and at Messrs. Weyher and Richemond's in Paris, have agreed closely with the tests made on the same turbo generators before they left the works at Gateshead. These tests have therefore confirmed the accuracy of the figures above given. 
Durability.-After three years' working of ten hours daily, the wear on the bearings has been found to be very small; in some cases almost inappreciable. The blades or vanes of the turbines show no eutting action from the steam. The commutators in the larger sizes have stood this amount of work well, and when carefully looked after have suffered very little wear.

Advantages. - The characteristic advantages of the turbo-electric generators may be summed up as follows:- steadiness of the electric current produced, arising from the high speed and the momentum stored in the moving parts; freedom from accident, on account of simplicity and direct action; small first cost, and small cost of maintenance of machine and lamps; small consumption of oil ; little attention required; small size and weight for the power developed, which is about nine watts per lb. of weight in the whole machine, including both engine and dynamo. Consequently they are specially suitable for torpedo boats and fast cruisers, where weight and space are of the utmost importance.

The number of these generators already (August 1888) supplied for ship and land installations represents an aggregate of more than 2,000 electrical horse-power.

Discussion, 1 August 1888.

The Hon. Chartes A. Parsons exhibited a couple of specimens of the engine of different sizes, one with the cover removed to show the construetion and arrangement of the series of turbines.

The President said all would admit that this was a new departure in high-speed steam engines, and the Members were very much obliged to the author for having brought this paper before the Institution. Judging from the drawings and the engine exhibited, 
it appeared to him that the author had successfully overcome a great many difficulties which had hitherto beset high-speed engines. Considering that his engine could run at 18,000 revolutions a minute, without developing a large amount of friction, and without great consumption of oil and steam, it was clear that he had pretty well solved a problem which a good many engineers had been trying to solve.

Mr. Jozn Stungeon was particularly interested in this motor, because he was just now on the look out for a motor suitable for driving dynamos by compressed air for the purpose of electric lighting, to work in connection with the compressed-air power supply which would soon be in full operation in Birmingham. The idea there entertained was that the proper way to arrive at the desideratum of private electric lighting was to convey the motive power to the users, and by means of some apparatus of this description to enable each user of the electric light to apply his own dynamo on his own premises, thus enabling him to avail himself of the latest improvements. One of the disadvantages of supplying electricity from a central station was that the town would be committed on a large scale to a particular electrical apparatus, and unable to avail itself of progressive improvements without incurring heavy expense in alterations. Another drawback was that an electric lighting company had only the night hours during which to earn their profits, while during the whole of the day they had still to keep up their staff of men and their apparatus and to pay interest on their outlay, all for the sake of a period of about a thousand hours in the whole year, during which their establishment could be turned to profitable account. He had been informed that in Leamington the experience had been unfortunate in an endeavour to supply the electric light by distribution of electricity from a central station. On the other hand when motive power was supplied by a general distribution, so that it could be applied to a number of different purposes, as was intendẹd to be done by the Birmingham eompany with which he was connected, the power could be used during the day for some three thousand working hours in a year; 
(Mr. John Sturgeon.)

while in addition electric lighting when carried out on that plan would employ a further thousand hours of night work. Thus the distribution of motive power would practically enable four years' work to be done in the time of one year's work done by direct electric lighting from a central station where the work would be confined to the night hours. In Paris compressed air had already been extensively applied to electric lighting. By reason of the greater facilities afforded by the municipal authorities in Paris, M. Popp, who had for some time previously been working a compressed-air system for driving clocks, had been enabled, since the present work had boen begun in Birmingham, to lay on a greatly extended system of compressed air, by means of which dynamos were driven for electric lighting in many of the principal buildings in Paris. Compressed air, he believed, would be much superior to steam for driving the turbine described in the paper, owing to the fact of air being practically double the weight of steam at the same pressure, and therefore much more suitable for the high-speed turbine, which by that means could be worked without the slightest inconvenience even in a private house. He should particularly like to have an opportunity of testing the apparatus with compressed air in Birmingham.

Mr. Henry Davey regarded this as the first real and successful rotary steam engine. Previous attempts at rotary steam engines he considered had in all cases been reciprocating engines, with the reciprocating parts more or less concealed under an appearance of constituting a rotary engine. Hero's reaction engine of two thousand years ago, the first steam engine ever made, had been a pure rotary engine; and the engine now described followed on its lines in that respect. It appeared to him that there must be a considerable diffeulty here as regarded leakage; and he should like to have the benefit of the author's experience in reducing leakage. It was also difficult to see how this high-speed engine was to be applied to various purposes requiring lower speeds, such as marine propulsion and driving machinery generally. One obvious way of getting out of the latter difficulty would be by making the engine 
larger in diameter, in the form rather of a fly-wheel than of an engine shaft like that now exhibited. He enquired also whether it was contemplated to make this a condensing engine, and if so what increase in economy was expected to be got from it thereby ; it would be difficult to apply an air-pump of the ordinary reciprocating form to such an engine, but possibly some form of centrifugal air-pump might be devised which conld be put direct on the turbine shaft and so answer the purpose in a simple way.

The most valuable part of the paper he considered to be the prectical results which had been obtained; these were exceedingly good, and rather startling from an engine so entirely new and so lately put to work. The commercial efficiency of the dynamo was given (page 485) as 95 per cent.; and assuming 80 per cent. effioiency for the motor alone, the total mechanical efficiency would then be represented by $35.1 \times 0.95 \times 0.80=26 \frac{1}{2}$ lbs. of steam per indicated HP. per hour. That was a good result for an ordinary engine but the best engines, such as triple-expansion maxine engines, had a consumption sometimes considerably below

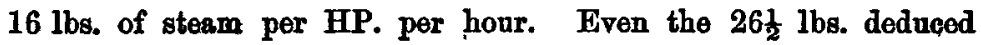
from the author's lowest statement of $35 \cdot 1$ lbs. appeared a muah better result than he should have anticipated from the steam turbine, taking into consideration the loss by leakage and the difficulties in manufacture in producing the exact form necessary for the blades and so on. The anthor appeared to have departed from his original design of having a continuous expansion from beginning to end : instead of this he had here reduced the expansion to three stages, more nearly approaching the action in tripleexpansion reciprocating engines. This alteration he thought a very good step indeed, whereby probably a much higher result would be obtained than by a strictly continuous expansion.

The Very Rev. Dr. MoLloy mentioned that the author had been good enough two months ago to send him this engine to show at a lecture that he had given at the Royal Dublin Society, at which it had worked most satisfactorily, producing an electric current for the supply of incandescent lamps. Both from the description now 
(The Very Rev. Dr. Molloy.)

given of the engine and also from his practical experience of its working, he had no hesitation in saying that for the purpose of electric lighting it was in the highest degree satisfactory. It gave promise of turning out one of the most important inventions of the present day. Its special merit for the purpose of electric lighting consisted in its perfect steadiness of action; and so far as he could judge from the theory of the engine, the pressure upon every blade in the turbines during the time of its operation, after it had reached its normal velocity, must be perfectly constant. In this respect it differed from every other form of engine at present existing; for in all other forms of engine the expansive force of the steam was applied in a succession of impulses, and these impulses being imparted to the dynamo naturally tended to produce unsteadiness in the electric light. Every impulse in the engine was accompanied by a change in the strength of the current produced, and every change in the strength of the current was attended by a corresponding change in the intensity of the light: so that, when incandescent lamps were fed by a current direct from a dynamo driven by any existing form of steam engine, the impulses of the engine could actually be seen in the pulsations of the light. That was a serious obstacle to the use of such lamps for the purpose of reading. So far as he could judge, this engine was capable of driving a dynamo so steadily as to furnish a current which would be perfectly constant, and incandescent lamps fed by the current would not be subject to any pulsation whatever. He desired to express the highest admiration for the extreme beauty and simplicity of this invention; and he trusted it would fulfil the expectations to which it had given rise.

In reference to the suggestion (page 488) that compressed air could be employed more satisfactorily than steam for working such an engine as this, it seemed to him that there would be no advantage in the use of compressed air which did not attend the use of steam. On the contrary there would seem to be a needless waste of energy, as it would be necessary to use steam power first to compress the air, and then the compressed air would have to do exactly that which the steam was capable of doing by means of this engine most efficiently of itself. 
With respect to the dynamo described in the paper, of which it was mentioned (page 485) that the commercial efficiency was 95 per cent., he asked whether by commercial efficiency was meant the ratio of the electrical horse-power produced in the external circuit to the mechanical horse-power expended in driving the dynamo: understanding by the electrical horse-power of the external circuit the total electrical horse-power of the current produced minus the portion wasted within the dynamo itself. If he was right in understanding the commercial efficiency in this sense, then it would seem from the paper that this dynamo had the highest efficiency of any dynamo yet produced. In the Edison-Hopkinson dynamo, which had been subjected to tests of the most delicate kind, the commercial efficiency obtained had varied from about 85 to 93 per cent. No dynamo that he had before heard of had attained a commercial efficiency of 95 per cent., which would be very high indeed.

The Hon. Chardes A. Pargons said the use of compressed air in the turbine had not yet been tried practically; but theoretically Mr. Sturgeon was quite right (page 488) in expecting a rather better duty than could be obtained with steam. Compressed air being heavier, the speed of its outflow through the turbine would more nearly agree with the speed of the blades, and the resulting efficiency would consequently be rather higher. Perhaps one difficulty would be that the compressed air would probably require to be heated, otherwise ice would be formed in the passages botween the blades, due to the expansion of the air ; but if the air was heated to $180^{\circ}$ or $200^{\circ} \mathrm{Fahr}$. that would probably be prevented.

Leakage had certainly been a great difficulty to overcome (page 488), and it was necessary to ran the blades as near as possible to the casing in order to reduce it to the utmost extent. By recent improvements in workmanship the leakage had now been reduced to a considerable degree; and no doubt it would still be much further reduced in the future. At present indeed leakage was the principal cause of loss.

The Prasidenst asked what was the amount of clearance between the blades of the turbines and the casing of the engine. 
Mr. Pansons replied that the clearance was only 0.015 inch in the larger machine exhibited; and this clearance represented a leakage of about 15 or 20 per cent. This engine was capable of working up to $50 \mathrm{HP}$. with $90 \mathrm{lbs}$. steam pressure. The smaller machine exhibited was about $4 \mathrm{HP}$, and would work about thirty 16-candle-power lamps.

There was no reason why the engine should not be used as a oondensing engine (page 489). Thus far there had not really been any opening for a condensing engine on this plan, and he had not yet made one; but the resulting efficiency would probably be very high indeed. The blades would of course be larger for dealing with the lower pressures of steam, and the leakage would be less: so that it would probably make a very good engine with very high efficiency.

With reference to the steam consumption (page 489), it was quite right to infer that, with a dynamo giving an efficiency of 95 per cent. and an engine giving 80 per cent., the consumption of steam at 90 lbs. pressure would be $26 \frac{1}{2}$ lbs. per mechanical horse-power per hour. But having calculated out the actual efficiency of this motor, he had found it amounted to only between 50 and 60 per cent., while the dynamo gave 95 per cent.; and the theoretical consumption of steam at $90 \mathrm{lbs}$. pressure in a perfect engine exhausting into the atmosphere was about $18 \mathrm{lbs}$. weight of steam per mechanical HP. per hour.

As to the commercial efficiency of the dynamo (page 491), the cause of its being so high was the high speed. As the magnetising current necessary to keep up the magnetism in these magnets was only about 1 per cent. of the total current produced by the machine, a larger loss could be afforded in other places. The loss in the conducting wire of the armature was very small, only 1 or 2 per cent. The energy required to magnetise and de-magnetise at so high a speed the iron core of the armature, although composed of very thin iron discs, jet constituted a considerable portion of the total loss.

In conclusion he wished to say that he was much indebted to Mr. Cross of Newcastle, Mr. William Anderson of Erith, and 
Professor FitzGerald of Dublin, for the valuable assistance they had given him in the development of both the dynomo and the motor.

The Prusmina considered this paper was too raluable for the diseussion upon it to be olosed at present. He would therefore not ask the Members to pass a vote of thanks to the author now, but would adjourn the discussion in order that it might be resumed at the next meeting, at which no doubt further information would be elicited on this important subject.

Adjourned Discussion, 25 October 1888.

The Hon. Ohartes A. Parsons exhibited a turbo-electric generator of about 7 H.P., which would work about sirty 16-candlopower lamps. He showed also separately the epizdle of a triple compound turbine of about 20 H.P.; and numerous eppecimens of the revolving amd stationary rings of blades, for spindles and casings of various sizes; and specimens of the bearings, and the steel washers composing them; and an armature.

The Cenarmar said the turbo-electric generator supplied to his firm at the Ormeshy Iron Works, Middlesbrough, had now been at work there for about twetve months, and they ware extremely pleased with it. The first outlay, as stated in the paper, was comparatively small, amounting in this case to $\$ 716$ 178. $11 d$. For that sum the machine had been applied to seven arc-lamps of 3,000 candle-power each; but now the same apparatus was found to be capable of doing far more work, and in a short time they expected to have it working with eleven lamps of the came power. The annual expenses also were moderate, amounting to $£ 131$ 14a $4 d$., which included an annual overhanl, earbons costing $£ 65$, brushes $£ 13$, oil $£ 6$, other stores $£ 13$ bs, and labour $£ 23$. It was necessary

2 B 2 
(Mr. Charles Cochrane.)

to go through the whole apparatus every twelve months to see whether it was in perfect order, which was done at a cost of $£ 119 s .4 d$. These figures were based on the actual results of six months' working, and were exclusive of steam, and interest and depreciation; the cost of maintenance and repairs might possibly increase with age. There was some difficulty in ascertaining the quantity of steam consumed, because it was taken from the gas-fired boilers that supplied the blast-engines and hoists, \&c.; but the representations made by Messrs. Clarke Chapman and Parsons with reference to their contract had been found to be so fully borne out that he believed complete reliance might be placed upon what they had stated to his own firm in regard to steam consumption :-namely that each lamp of 3,000 candle-power required 11 I.H.P., and that the generator consumed $3 \frac{1}{2} \mathrm{lbs}$. of coal per I.H.P. per hour. The coal consumption per hour would thus be $31 \mathrm{lbs}$. for the seven lamps, and the corresponding steam consumption 337 lbs. per hour, taking the evaporative duty of the Roots boilers used at Ormesby as 11 lbs. of water per lb. of coal. The average time of burning each lamp throughout the year was 50 hours per week. Hence the total steam consumption per year was 391 tons; and the equivalent coal consumption per year would be $35 \frac{1}{2}$ tons, costing $£ 10148.6 d$., if coals instead of gas were used for raising steam. Adding $7 \frac{1}{2}$ per cent. for depreciation and 5 per cent. for interest on the original outlay, and taking the foregoing estimate of the other annual expenses, with the addition of certain extras connected with the early working of the apparatus, the cost per lamp of 3,000 candlepower was found to work out to $£ 38$ 128. $1 d$. per year, or $3.57 d$. per hour.

Everything was beautifully balanced in the generator; as described in the paper, the longitudinal forces or end thrusts balanced each other perfectly, in consequence of the outflow of the steam towards each end alike from the central inlet. The author he believed had some special means of grinding the spindle for greater accuracy, not trusting to the ordinary strength of the spindle against the pressure of the tool upon it, but protecting it from defloction by grinding it in successive short lengths strongly 
supported, and so getting more perfect work by instalments along the whole length of the spindle, thus producing the magnificent work seen in the spindle now exhibited.

Sir James N. Dovgrass, Member of Council, said he had watched this instrument from its early development, and had had several opportanities of closely inspecting it; and he was full of admiration for the beautiful contrivance which the author had succeeded in so far perfecting. There were several very important points connected with it: one was the high speed, and another the perfect steadiness of action. With regard to the latter, he might mention that when visiting the Glasgow exhibition he purposely went a second time in the evening in order to see some of the electric lighting machines at work, especially the one described in the paper. Although he had seen it several times before, he confessed that he was so perfectly deceired by its steadiness as to ask the attendant whether the machine was going to be run. There was the machine itself running before him, but so steadily that there was no visible sign of motion and no flash of the commutator; and it was only on examining it closely that he found it was actually running. That was enough he thought to satisfy any practical mechanic that the machine was almost absolutely perfect for its purpose; because steadiness of motion was a most essential quality in a dynamo, for removing from the commutator all vibration, and so preventing flashing. No doubt the author had already improved the machine very considerably with regard to economy; but even if it were not a perfect machine in economy of steam for the other applications that had been suggested, its great value for installations afloat was seen in its lightness and the very small space it occupied. Indeed even if it were extravagant in steam, the amount required to drive it was a very small fraction of the total consumption for propelling the ship; consequently any small saving effected in driving the dynamo was of no material consequence. Examples of great disregard for economy frequently occurred in the rough and ready donkey engines used at sea; there was perhaps very elaborate and perfect machinery on board for driving the ship, but the donkey, which was absorbing as 
(Sir James N. Douglass.)

much steam as the electric installation and perhaps more, was very often of the rudest description and very extravagant in steam. The Members of the Institution had reason to congratulate the author on the very successful and perfect machine which he had brought before thom.

Mr. W. Wonbr Beaumont asked whether this motor had been tried with steam pressures higher than that mentioned in the paper (page 485) of 92 lbs.; and if so whether the increase in the pressure was attended by anything like an increase in economy corresponding with that represented by the two figures given. With 61 Ibs. pressure the steam used was stated to be $42 \mathrm{lbs}$. per electrical horsepower per hour, and with $92 \mathrm{lbs}$. pressure the consumption was reduced to $35 \cdot 1 \mathrm{lbs}$. Did a similar fall in consumption occur with still higher pressures?

Mr. Graberr Kapp said it was a full year since he first becamo acquainted with this engine and had an opportunity of testing it, which was a long time, considering the rapid developments that had taken place. The occasion was at the Newcastle exhibition, at which it had been his duty as one of the jury to be very critical, and to detect if possible any defects in the machines exhibited. But although having previously had an unfavourable opinion of this new contrivance, the tests then made had fully convinced him of its merits. The turbine there tested was not one of the triple kind. It was taken in the morning from its masonry pedestal in the exhibition to the works of Messrs. Clarke Chapman and Parsons in Gateshead, and was put under steam in the afternoon and kept running for four hours. The water consumed was carefully measured, and the electricity developed was also measured. From these measurements, which were as accurate as they could be when taken in an ordinary trial without elaborate preparations, the consumption of water was found to be a little over $50 \mathrm{lbs}$. per electrical horse-power per hour. The lights were exceedingly steady, the high-speed machine producing absolutely no vibration that could be seen, either in the machine itself or in the lights. There was however a sound in the lamp, something like 
the humming of a bee or of a tuning-fork. This curious effect he had not noticed with any other dynamo, and he did not know whether it was peculiar to the machine, or whether it was simply an accidental effect at that trial; perhaps the author would state whether he had noticed it in any other case. The hum might have been either in the lamp itself or in the wires which led to it; but it was difficult to distinguish where it was. The lamp was in the photometer, and the box of the photometer might have acted as a kind of sounding board. As far as he could make out, the note of the hum heard at the lamp seemed to be about the same as that which he heard again when close to the dynamo.

With regard to the dynamo itself, the idea of running it at very high speed was excellent, because speed was much cheaper than iron or copper. But it was necessary to use some precautions. The author's magnets were made of cast-iron, which those who were accustomed to the old-fashioned dymamo considered a bad material; and when he first saw this dynamo he thought a much better maohine might heve been made of wrought-iron. But since then he had found out that it was perfectly right to make them of cast-iron, because if they had been made of wrought-iron they would have produced such a powerful field as to call forth in an excessire degree a certain magnetic effect which had lately been discovered by Professor Ewing and had received from him the name of hysteresis. According to modern views magnetisation was accompanied by a rotation of the molecules, and they apperred to have an aversion to being rotated, and if it was done too much they showed their dislike by getting hot. Therefore machines which were run very fast should not be very powerfully excited; and the anthor had accordingly done right in adopting such magnets as would not produce that effect. By having a cast-iron magnet and working in a fairly weak field, the heating effect which troubled rery many dynamos was avoided. The arrangement of the armature winding was also a good one. The author had adopted what was usually known as the drum-winding, in which there was very little self-induction; and hence it was found that there was no sparking at the commutator, as had been pointed out by Sir James Douglass (page 495). 
Mr. William Schönhryper understood the object of the bearing shown in Fig. 6, Plate 87, was to allow the spindle of the turbine to centre itself about its own axis of mass, which did not necessarily coincide with the geometrical centre of the mass. In that respect the spindle when running at a high speed was trying to do the same thing as a spinning-top, and it seemed to him that it might be looked upon as an eccentric revolving round a central axis; therefore the rotation must be continually throwing the journal from side to side and from top to bottom, once in every revolution, to a very small extent, which must result in giving the bearing a series of blows at the rate of 18,000 per minute, or whatever the number of revolutions might be. Those blows were taken up in the bearing by the friction of the washers one against another; and it appeared to him that this must be very much to the detriment of the bearing. That it ran well and satisfactorily might be due to the fact that it was really in balance, or very little out of balance, and that the lubrication was so good that no harm took place. But it seemed to him that the proper way of making the bearing would be to cause the whole of the washers to revolve with the spindle, making it of course suitably smaller, and to surround them outside with a cylindrical steel casing or sleeve, which should also revolve with the spindle and would then form the bearing; the spindle would thas be able to knock the washers to one side or the other within the casing, so that the centre of the mass would ultimately coincide with the centre of the outside casing or sleeve which formed the bearing.

Mr. Benjamin A. Dobson, Member of Council, said that, being somewhat familiar with high-speed " bearings, he had had his admiration first awakened for this machine by an examination of the beautiful device for overcoming the practical difficulty that arose in making the mass of the turbine revolve at the high speed at which it was driven. A weight of only two grains at the extremity of the largest diameter in the triple compound turbine would represent at the speed at which it revolved a centrifugal force giving a blow of $2 \frac{1}{2} \mathrm{lbs}$. up and down and sideways in each revolution; and it was hardly practicable to construct any shaft of that diameter without its being 
at least two grains out of balance. Even so small a want of balance would be sufficient at such a high speed to cause an immediate wear in the bearing, supposing it were a hard and fast bearing such as was ordinarily used for lower speeds. First it would wear at the bottom, because in addition to the friction of the rotation there was the weight of the turbine itself. As soon as there was the slightest degree of wear at the bottom, there would be an up and down motion which would gradually wear the bearing elliptical. That would have proved an absolute bar to the employment of this machine, if it had not been for the anthor's device; because the amount of clearance was so little between the revolving blades on the turbine and the stationary guide-blades in the casing that a very trifling amount of play, such as would hardly be considered appreciable in ordinary machinery, would be sufficient to cause contact all round and thereby make the machine impracticable. The finding of the centre of gyration, or rather allowing the turbine itself to find its own centre of gyration, was a well-known device in other branches of mechanics: as in the instance of the centrifugal hydro-extractor, where a mass very much out of balance was allowed to find its own centre of gyration; the faster it ran, the more steadily did it revolve and the less was the vibration. Another illustration was to be found in the spindles of spinning machinery, which had to run at about 10,000 or 11,000 revolutions per minute; they were made of hardened and tempered steel, and although they were of very small dimensions, the outside diameter of the largest portion or driving whorl being perhaps not more than $1 \frac{1}{4}$ inch, it was found impracticable to run them at that speed in what might be called a hard and fast bearing. They were therefore run with some elastic substance surrounding the bearing: either steel springs, or hemp, or cork, or india-rubber, which last howerer was of course objectionable in consequence of heing deteriorated by the oil. In fact any elastic substance was sufficient to absorb the vibration, and permit of absolutely steady running. The washers forming the bearing described in the paper had a very small difference of diameter, which allowed the turbine a free vibration of that amount; but at the bigh speed at which it was running of 10,000 or 12,000 revolutions a minute or upwards it was obvious that it 
(Mr. Benjamin A. Dobson.)

would be impossible for that vibration to occur in its entirety in each revolution. The object of the device was to neutralise the tremor by allowing a slightly eccentric motion to the bearing itself; this was divided amongst the two sets of washers; and as the lubrication was constant and the oil was continually pouring abundantly over the bearings, the amount of wear and tear was very slight indeed. The object he presumed of the spring which pressed the washers together was to put sufficient friction upon them for overcoming the difference of equilibrium that might exist initially in the turbine when beginning to rotate at a low speed. If the spring was strong enough to overcome that, it was evident there would be no shock, because the same friction would be equal to the action of the smaller vibration at the higher speed. Having himself made a number of experiments with regard to the bearings of spindles running at high speeds, he had found that as a rule, with hard and fast bearings, if it was a spindle in extension -that is, supported only at one end and at the middle, with half its length projecting unsupported-there was a particular speed, varying according to the weight and diameter and overhanging Jength of the spindle, at which it was impracticable to run the spindle when there was the slightest want of equilibrium, in consequence of its excessive vibration. When this was found to be the case, it would very often be discovered that on increasing the speed the vibration would in a great degree disappear. It was indispensable with that class of bearings that there must be a high speed; because if the speed was slow, and the want of equilibrium was sufficient, there was at each revolution a shock which it was necessary to avoid. In the small spindles with which he was himself accustomed to deal these phenomena were very remarkable indeed. In some instances an addition of 1,000 revolutions per minute would alter a spindle running badly to a spindle which ran very well. He had not been able to discover that there was any limit to the extreme of speed; having gone up to 17,000 and 18,000 revolutions a minute, which was as much as could well be measured, he had not found that there had been any change after say 15,000 revolutions had been passed. But from 4,000 up to 8,000 revolutions per minute, according to the make and weight of the spindle, the diameter of its bearings, and 
general conditions, there was a very remarkable divergence of behaviour, so much so that it was impracticable to decide upon the exact proportions of the spindle; and therefore every one who had to do with such opindles had been obliged to come to the practical adoption of some sort of elastic bearing for them. He should be very glad to know if any of the Members had had any experience in that respect, and whether they could define the law which governed the vibration in those particular cases. Although he had not yet had the pleasure of seeing this machine at work, he was convinced from the description which had been given, and from an examination of the elastic bearing, that it would run, as Sir James Douglass had said, absolutely without vibration and noiselessly. The combination of the suction-fan, the leather diaphragm, the spiral spring, and the airpipe as a centrifugal governor, he considered to be one of the most ingenious things it had been his good fortune to see; and he was sure it would require long and careful study before engineers could devise anything that would much surpass this compound turbine engine.

Mr. HunkX Davrix remembered that at the time of the description being given to this Institution (Proceedings 1882, page 519) of De Laval's centrifugal separator for separating cream from milk, which ran at a very high speed, there was considerable difficulty with the bearings on account of the gyratory motion. Since that time however the bearings had been modified by surrounding the upper bearing with an elastic band instead of a rigid collar; and this modification had made the machine perfect. The accidents that nsed to happen to it never happened now, owing to that particular expedient, on which $\mathbf{M r}$. Dobson had rightly insisted (page 499), of surrounding the bearings with an elastic substance.

In continuation of his previous remarks in Dublin (page 489) with regard to the economy of the compound steam turbine, although it might not be a very economical machine, yet for so small an engine he thought it was fairly economical. In the author's previous reply (page 492) only between 50 and 60 per cent. had been given as the actual efficiency of the motor; but the mechanical 
He also asked whether in designing and making the stenm turbines they were made applicable for all pressures, so that the best results could be obtained alike with all steam pressures and at all speeds. In turbines for water power the best result could be obtained only at one particular speed and with one particular pressure or head of water for each individual turbine. If the same was the case with the steam turbine, what loss of efficiency was to be expected from a reduction in the pressure or in the speed?

Mr. Anthur PaGRT, Vice-President, in explanation of the reason why the revolution of a badly balanced and therefore oscillating body might in some cases absorb more power at a lower speed and less at a higher, referred to a former discussion upon a paper read before this Institution on thrashing machines (Proceedings 1881, page 401), in which it had been pointed out by Mr. Pendred that the rate of oscillation of the reciprocating shoes or sieves under the straw-shakers ought to be synchronous with that due to the length of their hangers considered as pendulums; and if they were driven at any other than that speed, either slower or faster, more power would be required. If that principle were applied to the spindles referred to by $\mathrm{Mr}$. Dobson (page 500), which were not perfectly in balance, he thought it would be found that the least power would be absorbed in driving them when the speed of revolution was made to correspond with the speed of oscillation of the extremely short pendulum which would represent the minute want of balance in the spindles.

The present paper was the second in which there had been brought before the Institution a high-speed engine of great efficiency and beautiful working as far as lubrication went. The honour and credit of its merit in this last respect he thought might fairly be said to belong to this Institution; for the lubrication of the engine now described appeared to depend entirely upon the oil not being fed in a niggardly manner, drop by drop, but being actually driven through the bearings by the feeding screw. Similarly in regard to his spherical engine it had been properly stated by Mr. Tower (Proceedings 1885, page 115) that its success was mainly due to the same cause, namely that the oil was not dropped in with a 
He also asked whether in designing and making the steam turbines they were made applicable for all pressures, so that the best results could be obtained alike with all steam pressures and at all speeds. In turbines for water power the best result could be obtained only at one particular speed and with one particular pressure or head of water for each individual turbine. If the same was the case with the steam turbine, what loss of efficiency was to be expected from a reduction in the pressure or in the speed?

Mr. Anthur Pagit, Vice-President, in explanation of the reason why the revolution of a badly balanced and therefore oscillating body might in some cases absorb more power at a lower speed and less at a higher, referred to a former discussion upon a paper read before this Institution on thrashing machines (Proceedings 1881, page 401), in which it had been pointed out by Mr. Pendred that the rate of oscillation of the reciprocating shoes or sioves under the straw-shakers ought to be synchronous with that due to the length of their hangers considered as pendulums; and if they were driven at any other than that speed, either slower or faster, more power would be required. If that principle were applied to the spindles referred to by Mr. Dobson (page 500), which were not perfectly in balance, he thought it would be found that the least power would be absorbed in driving them when the speed of revolution was made to correspond with the speed of oscillation of the extremely short pendulum which would represent the minute want of balance in the spindles.

The present paper was the second in which there had been brought before the Institution a high-speed engine of great efficiency and beautiful working as far as lubrication went. The honour and credit of its merit in this last respect he thought might fairly be said to belong to this Institution; for the lubrication of the engine now described appeared to depend entirely upon the oil not being fed in a niggardly manner, drop by drop, but being actually driven through the bearings by the feeding screw. Similarly in regard to his spherical engine it had been properly stated by Mr. Tower (Proceedings 1885, page 115) that its success was mainly due to the same cause, namely that the oil was not dropped in with a 
(Mr. Arthur Paget.)

sparing hand, but was forced abundantly through the bearings. No doubt the author of the present paper wonld himself be the first to acknowledge that the experiments of the Research Committee of the Institution on the friction of bearings at high speeds had led him to adopt the admirable plan of forcing oil abundantly through his bearings; and probably it might not unfairly be said that this ample lubrication had contributed materially to the success of his steam turbine and dynamo.

Mr. W. Sruver HaLx mentioned that some time ago he had met with a very efficient kind of lubricator, consisting of a close-topped box, containing a sort of stiff grease. By screwing down the top of the box from time to time, a little of the grease was forced into the bearing; and it was impossible for the grease to be thrown out from the bearing through the oil hole, because that oil hole was sealed by the screwed cover. That lubricator, which had been used by himself for ordinary purposes, would act he believed in keeping a bearing cool in cases where any ordinary lubricator, which would permit the oil or grease to flow in and out, would fail. The only way in which the grease could escape with that lubricator was of course endways along the bearing; and so in the bearing described in the paper, the oil appeared to be continuously held to the bearing, and could not get awry except by traversing right over its whole length.

Professor Gmonan Forbes was glad to have this opportunity of testifying to the feeling with which electrical engineers regarded the beantiful engine brought before them by the author. Most of them he believed would agree that but fow substantial advances in connection with dynamo electric machinery had taken place during the last fifteen years. Since the invention of the dynamo machine by M. Gramme he thought the three most important advances which had been made and which would always be remembered in connection with dynamo electric machinery were the system of distribution by transformers by Gaulard and Gibbs, the alternatingcurrent motor of Tesla and Ferraris, and now the turbo-electric 
gemerator of Mr. Parsons. Most of the other improvements in dynamo electrio machinery had been purely in matters of proportion; but in those three inventions there had been real brain-work, and in none of them was there such an amount of original invention and brain-work as in the turbo-electric generator. It was true this was more the case in the mechanical parts than in the electrieal parts; but each part displayed distinct inventive ability, which required also considerable conrage for its development into practical realisation. Whether in the bearings, or in the electric governing, or in the various other parts, it was a new contrivance altogether. From an electrical point of view he was struck with the beauty of the dynamo machine and of the electric governing; the latter he thought was more perfect in this than in any other arrangement he had ever met with. Having watched the machine carefully in a considerable number of places where it had been put to work, he had been much struck in every case with the perfection of the mechanical details. A few months ago he had had the oppostunity on board the "Oity of Berlin" of spending a great part of the royage from New York in company with Mr. Webb, the engineer of that steamer, on which two of these turbo-electric generators were in use; and what had struck him most, in comparing this vessel with the other Atlantic liners on which considerable attention was required by the dynamo electrio machinery, was the almost total absence of attention in connection with the running of the turbo-electric generator during the whole nine or ten days of the voyage. One little accident happened to one of the turbines during the royage, but it was a thing which might have happened to any other piece of machinery. The working generally was extremely perfect, requiring so very littlo attention, and was satisfactory to every one who had to deal with it.

The theory of the compound steam turbine presented many points of interest. One especially was that, when the engine was first introduced, it was thought by some that there would be a great loss of power from the friction of the steam passing through the series of turbines; whereas one of the most beautiful thingw about it was the almost total absence of any loss of power from that cause. 
(Professor George Forbes.)

The greater the friction in its passage through the turbines, the drier was the steam and the greater was the efficiency of the whole apparatus; the heat developed by the friction was being utilised all the time in making the machine more perfect.

With reference to accidents, it would of course sometimes happen that the bearings would wear, and that collisions would consequently occur between the blades on the spindle and those in the casing, resulting in their mutual destruction; and he wished to know whether in actual practice such accidents had been found to be of frequent oceurrence, or only rare. The washers could of course be replaced pretty readily; any information about the wear of the spindle would be interesting.

With regard to economy, he had not had the good fortune to be able to make any tests on the consumption of steam; but he thought the statements made in the paper might be accepted as being accurate. The economy was certainly extremely good already, though the engine worked non-condensing; and all were looking forward to the probability that when the author introduced condensing, as he believed he intended to do, there would be a great step in advance, and this machine would probably be as economical as any means now known of generating electricity: for it must always be remembered that the high speed of this dynamo machine tended to make it the most economical and efficient of any of the contrivances for the development of electrical energy. There was one defect howerer in regard to the application of the turboelectric generator to central station work, namely the noise which it created. It was certainly a veritable siren; and it became a question how far its noise could be deadened, so that it might be possible to introduce it into the centre of a town without its being a nuisance. This object he believed could be accomplished thoroughly by proper means. In the installation at Lincoln's Inn, London, the dynamo room was lined with felt, and by that means the noise in the room was completely shut off from the street. But the noise was carried on by the steam pipes into the boiler room, where it came out. It had however been suggested, and it was probably true, that the noise would be much diminished by having the pipes bent 
where they passed from the dynamo room into the boiler room. At any rate he felt great confidence that the question of noise could be dealt with efficiently in some way or other; and that was the chief objection he had seen to the machine.

Beyond the uses to which it had been at present put, he thought he saw a great field for its future development, not only by the condensation of the steam, but also by the possibility of its use as an alternating-current dynamo machine. At the present time alternating - eurrent dynamo machines constituted the most important means of distributing electricity from central stations; and until quite lately at any rate those machines had been very imperfect indeed. The class of machine with only two poles was far more perfect than that with a great number of poles as ordinarily constructed. It had occurred to him some time ago to suggest that the high speed of rotation of the turbo-electric generator rendered it extremely easy to convert it into an alternating-current dynamo, by putting two insulated rings over the commutator, connecting one with one commutator bar and the other with the opposite commutator bar. That experiment had lately been tried by the author, and he had found that the machine worked splendidly as an alternatingcurrent dynamo in that way; and the heating of the pole pieces, which had been expected to prove a serious obstacle, was not so at all. When worked in that way it seemed to him to be the most perfect kind of alternating-current dynamo machine in existence. It ran at 8,000 revolutions per minute, making therefore 16,000 reversals; and it so happened that this number of alternations was just what had been found in practically successful alternating dynamos to be the best speed of alternation. Consequently for alternating currents the turbo-electric generator seemed likely to become in future the best of all.

Mr. Josmpr Rronmond asked what was the greatest number of lamps lighted by any one of the turbo-electric generators. It had been stated that there was a loss of only 5 per cent. between the motor and the dynamo, but that the efficiency of the motor was only betwcen 50 and 60 per cent.; thus showing a total loss of about 50 
(Mr. Joseph-Richmond.)

per cent. Would the author say what he considered to be the actral efficiency of the whole arrangement, in the relation of coal burnt to candle-power? There was a great future he considered for electric lighting, but at present there was competition to be met; and if gas was to be superseded for the lighting of parishes, large warehouses, stations, \&c., it would be necessary to go to the root of the cost, which would be the consumption of coal per candle-power. He should also like to know what was considered to be the wear and tear of the whole of the machinery. At an establishment with which he was associated, where there was a quantity of machinery and one of the turbo-electric generators was used, he intended to give it a separate boiler to itself, and to weigh the coal ont to the boiler, and take account of the number of lights in relation to the quantity of coal burnt. Meanwhile he certainly congratulated the author upon the ingenuity of the whole apparatus; every engineer would admit that the governor of the motor was as clever a piece of mechanism as had been seen for many a long day.

Mr. JoHn P. Franfield asked whether the author had ascertained from experience what was the relative efficiency of the compound steam turbine between wide ranges of load, as compared with that of an ordinary reciprocating compound steam engine. Could a compound steam turbine of 50 horse-power work as economically as a reciprocating compound engine of the same power with loads varying from 5 to 50 horse-power? If the efficiency of its working was limited to a constant load and a uniform speed, as when the dynamo was supplying a constant current with constant pressure, it could only be used with anything like economy either in charging accumulators, or for large are lamps which required a constant current or one varying only very slightly. In many electric lighting installations at the present time, as he believed would be the case with most of them in the immediate future, motors were required that would work economically between wide variations of load. For electric lighting in a large club or factory or warehouse, or on shipboard for search-lights, or in a light-house, or wherever the whole light was constantly wanted, he could understand that the turbo- 
electric generator might be very economical; it was no doubt an admirable piece of machinery. But those were exceptional cases. What the public required was a light that could be turned on and off just like gas, which could be stored in a large gasholder and supplied as required. It would not do to have dynamos driven by engines that would be far from economical when working under only a portion of their nominal load. In designing a plant for five hundred lights, there must be arrangements for working only ten or other small number; and the coal bill would be running up unduly, if the motor was not so designed as to bear great variations in load with a fair amount of economy. How economically the best compound engines of the present day were working was well known; but as yet he was not aware of any high-speed engines, directly coupled to generators, that were working anything like as economically with varying loads. Not that they did not work economically with one fixed load; but it was the varying load that interfered with their economy.

In regard to the number of lamps that any dynamo would drive, this depended a great deal upon the kind of lamps employed. The mere number of lamps was not a test of the work done by the dynamo; what was wanted to be ascertained was the amount of the current and the voltage.

Mr. Jmbemian Hrad, Past-President, was glad to have the opportunity of saying how much he admired this beautiful piece of mechanism. Although the originality and ingenuity displayed in the design and execution of the various details must call forth admiration, yet it must be borne in mind that after all the main peculiarity of the engine was the enormous speed at which it ran. Twenty years ago no one knew of anything more than about 300 revolutions per minute in practical running. Then came the Brotherhood three-cylinder engine, and afterwards the Parsons engine made at Leeds, which brought the possible number of revolutions up to perhaps 1,200 at the utmost. But here was a machine that went at 12,000 revolutions, and occasionally even at 18,000. This was an enormous stride in the way of velocity beyond anything that had been done before; and that fact should

2 s 2 
(Mr. Jeremiah Head.)

be kept well in mind. Of course so high a speed meant great power in a small space and for a small weight. Without having worked out any calculation, he ventured to think the compound steam turbine gave a greater power for its weight than any other kind of engine known. To engineers this afforded matter for much thought, because there were so many instances in the arts generally in which great power was wanted without great weight. One that occurred to him at the moment was aerial navigation. It had always been said for a long time past that it would be impossible to propel machines in the air because of the great weight of any engine which would be required to do it. If yet further progress could be made in the direction taken by the author, there was no telling what might be arrived at. If was rather a curious thing that the first steam-engine of which there was any historical record-namely that by Hero of Alexandriahad also been a turbine; and here, in the latest invention, the anme principle had been adopted: the only difference being that the former engine must have been an exceedingly wasteful one, while the present appeared to be fairly economical. He was not at all sure that the economy would not very soon be improved; because, if a condenser were added to it, this alone would produce some economy. But whether this addition wore made or not, $90 \mathrm{lbs}$. steam pressure seemed to him to be absurdly low for such an engine. In the very town where it was constructed, Gateshead, he had seen only a fow days ago a Perkins engine working at 400 lbs. pressure at the works of Messre. Hawks Crawshay and Sons; the steam gauge showed $400 \mathrm{lbs}$. per square inch, and the engine had been working for a long time with 24 expansions, and, as far as all appearances went, with success to itself and perfect safety to the boiler. He could see no reason why the author should not adopt the same principle for the steam turbine, and try a much higher pressure with more expansion; and perhaps he would see his way to do so.

An engine so distinctly novel had set him thinking in various ways. There were many places where not only was it important to have extreme lightness in the motor, in order to get as much 
power as possible for the least weight, but where it was also most important to avoid having to carry great weights in the shape of fuel and water. For instance there was the case of the steam plough working in a field, to which both the coal and the water had to be carried. In a good boiler $1 \mathrm{lb}$. of coal would evaporate about $10 \mathrm{lbs}$. of water; so that the $1 \mathrm{lb}$. of coal taken to any spot really meant a total weight of $11 \mathrm{lbs}$. to be carried thither. There were many other circumstances conceivable under which it was of the utmost importance to avoid taking such large weights for keeping up motive power. The only idea that occurred to him for meeting such cases-and possibly it might bo applicable to the steam turbinewas to use petroleum, which possessed about twice the evaporative power of an equal weight of coal. Therefore there was an advantage in burning petroleum under such circumstances, instead of coal. But if the petroleum could be burnt in the engine itself, as was already being done in the cylinder of the petroleum engine, it would save the water altogether: that is, it would save carrying the $10 \mathrm{lbs}$. of water for the $1 \mathrm{lb}$. of coal, and therefore the total weight of petroleum required to be carried would be reduced to something like one-twentieth of the present weight of coal and water together. Whether the products of combustion from petroleum could be applied to such a machine as the compound steam turbine he did not know; it would require a great deal more thinking out, but it did not appear impossible; and the sight of such an advance as was shown by this machine, beyond anything that had previously been done, had naturally set him thinking whether yet further progress might not be made in the same direction, so as to get enormously more power than had ever been thought of before for a given weight of machinery, and also very much less weight of coal and water used for it.

Mr. W. D. Scotr-Moncrierf noticed that in the previous discussion, in answer to observations made by Mr. John Sturgeon respecting the use of compressed air, the author had remarked (page 491) that, compressed air being heavier than steam, the speed of its outflow through the turbino would more nearly agree with the 
(Mr. W. D. Scott-Moncrieff.)

speed of the blades, and the resulting efficiency would consequently be rather higher. He gathered therefore that the author believed the compound turbine was suitable for the employment of compressed air as a motive power under conditions of considerable economy. But he then went on to say that the formation of ice in the passages between the blades, due to the expansion of the air, would probably be prevented if the air was heated to $180^{\circ}$ or $200^{\circ}$. No doubt the heating of the air in the case of the compound turbine would result in an economy equal to that resulting from the heating of the air for use in a reciprocating engine. But he would take the opportunity of pointing out that, if the air was to be used expansively in the compound turbine, probably the same rule would apply as that which to a certain extent he thought he had discovered in the use of compressed air in reciprocating engines: namely that the excessive loss of heat which led to the formation of ice in the working parts, especially at the points of exhaust, was really due, not so much to the absorption of the heat which was the mechanical equivalent of the work done in the cylinder, as to the fact of that absorption being further augmented by the loss which subsequently arose from the sudden expansion of the air, doing useless work amongst its own particles at the point of exhaust. In other words, the difficulties arising from the use of compressed air at ordinary atmospheric temperatures arose not from expanding the air too much, but from expanding it too little. He had discovered that, as soon as the expansion was carried to a point at which the residual pressure at the moment of exhaust was the pressure of the atmosphere, all difficulties with regard to freezing ceased: so that in an ordinary reciprocating engine the amount of heat which was absorbed as the oquivalent of the work done in the eylinder would not then produce sufficient cold to give trouble in the form of ice. As a matter of fact it gave trouble only when the air, having been already deprived of the heat due to the work done, was allowed to escape at a pressure considerably above that of the atmosphere. Possibly the same rule might apply to the use of compressed air in the author's beautiful compound turbine. 
Mr. J AMrs StabLer thought that, taking into account the relative pressure and velocity of the steam in its passage along the circumference of the revolving spindle in the compound turbine, the proper form for the outline of the spindle would be an adiabatic curve. He agreed with Mr. Head (page 510) that a higher pressure of steam might be used advantageously; but the highest pressure of say 300 lbs. per square inch should be admitted he thought upon the largest diameter and shortest length of the spindle, and should thence be expanded in a succession of steps, each of smaller diameter and longer length than its predecessor, until it was finally exhausted from the smallest dinmeter and longest length of the spindle. By thus reversing the progression of the diameters from that followed in the triple compound turbine described in the paper, the steam, as it became reduced in pressure and expanded in volume, would be enabled he considered to give off continuously its full effect. In that way he believed the whole power of the steam might be taken up. The want of economy which had resulted in the failure of the many rotary engines brought out during the last fifty jears had been the consequence in his opinion, not so much of leakage or of other defects in construction, as of neglect of the diminishing velocity of the steam in passing through; and unless this point was duly attended to, it seemed clear to him that it was impossible to obtain entire economy in the use of the steam supply.

Mr. P. W. Willans, referring to the intention expressed by Mr. Richmond (page 508) of weighing out the coal to the compound steam turbine, pointed out that such an ordeal was not always satisfactory, because it confounded the efficiency of the engine with that of the boiler; and he would therefore suggest weighing out the water instead of the coal, which he thought would give more useful information.

As to making a motor which would be equally efficient at all powers (page 508), that he believed would be exceedingly difficult to do with any engine, until an arrangement could be devised whereby its size could be reduced as the lights were turned off. Those 
(Mr. P. W. Willans.)

conditions could most nearly be approached for electric-lighting work by subdividing the power and using several motors.

With regard to steam consumption, the economy of the compound turbine with 61 lbs. steam pressure seemed remarkably good (page 485); but 35 lbs. of water per electrical horse-power per hour for 92 lbs. pressure did not seem to him to be a good result. At his own works with 92 lbs. steam pressure he was now getting an electrical horse-power for rather loss than 30 lbs. of water per hour. It would be interesting to know what would happen with the turbine when much higher pressures were used; he supposed that by lengthening the engine probably about the same efficiency would be arrived at in the cnd. The same result he imagined would probably follow from condensing trials, for which also he supposed the turbine would have to be lengthened a good deal.

Friction had been spoken of by Professor Forbes (page 505) as having been expected to prove the main source of loss in the compound turbine. It appenred to himself doubtful whether there would be such a great amount of friction; but even if there were, it further seemed improbable that this would all come back in the shape of power: inasmuch as any heat caused by friction would not be quite so usefully employed in the turbine as it was in the boiler, because in the turbine it would be employed in re-boiling at a later stage the water that was formed during the earlier stages of expansion, re-evaporating it at a low pressure and thus making low-pressure steam, just as a steam-jacket would do when going beyond its proper function. The main loss must he thought be that due to leakage, the limit to the economy of such a machine being fixed by the amount of clearance which for practical reasons it was necessary to allow.

The Hon. Charles A. Parsons, referring to the mention made by the Chairman of the mode of perfecting the finish of these machines by grinding the spindles, said it was difficult to get a sufficiently true spindle by merely turuing it in a lathe. All the spindles for the compound turbines were ground by an excellent automutic grinding machine made by Messrs. Smith and Coventry, which 
gave almost absolute truth. When the spindles came off the lathe, and were subjected to the grinding machine, they appeared to be three-cornered and all kinds of shapes; but the grinding machine gave thom a wonderfully true finish in the end. It had also been found difficult to get the bore of the casing absolutely true. When the spindle had been turned and ground as nearly true as possible, and had been covered with rings of blades, the complete moving part was then ground into the case with fine emery; and by that means they could run with a clearance of ouly about 1-64th of an inch all round, and sometimes rather less. There had been some difficulty from the expansion of the metal by the heat of the steam passing through; and tho parts were often ground first cold with small olearance, and were also ground in again when the cylinder was hot, so as to get as near a fit as possible in running. Whatever clearance there was initially did not increase, because it was found in practice that in consequence of the continuous lubrication the wear of the bearings was almost nil ; in fact in some instances after two years' almost continuous work the wear did not measure 1-500th of an inch in diameter. In the larger turbine, of 50 horse-power, there had been a certain amount of abrasion due to the knocking action which had been mentioned; and this had been got over by surrounding the steel washers with steel liners, instead of allowing their sharp edges to bear directly on the cast-iron.

With regard to the apparent discrepancy in page 485 between the consumption of $42 \mathrm{lbs}$. of water with $61 \mathrm{lbs}$. pressure of steam, and 35. 1 lbs. of water with 92 lbs. pressure, the difference arose from the two tests not having been made on the same machine. The 42 lbs. consumption was obtained with a 400 ampère machine; it was larger, and the speed of the blades was rather higher, more nearly approaching the theoretical speed at which they should run for maximum efficiency. The $35 \cdot 1$ lbs. consumption was obtained with a 300 ampère machine, which was not quite so perfect. In answer to Mr. Beaumont's enquiry (page 496), the economy was increased to a considerable extent when the pressure was raised, but at present the increase in economy was not in the same proportion as the rise of pressure should theoretically give: comparatively better 
(The Hon. Charles A. Parsons.)

results were obtained at lower pressures than at higher; in other words the consumption of steam as compared with that of a perfect engine was less at low pressures than at high pressures. But he hoped to get equally good results in the course of time.

The humming which had been observed by Mr. Kapp in the lamp at the works in Gateshead (pages 496-7) was due he thought to the fact that it was a 16-candle lamp, and was worked by a machine with a ten-part commutator. With this small number of sections there was a considerable variation of electromotive force during a revolution, which caused some molecular disturbance in the filament of the lamp. A much londer noise was produced by the same current when passing through iron wire resistance coils. The machines were now made with a fifteen or twenty-segment commutator, whereby the variation in electromotive force was much diminished; and the hum was not then audible.

For the magnets (page 497) wrought-iron had been tried, but it was not successful; there was not enough residual magnetism to start the dynamo. Cast-iron retained considerably more magnetism, gave as much power as was wanted, and was cheaper.

The steel washers forming the bearings of the turbine differed somewhat in principle from the india-rubber ring used in the milk-separating machines (page 501). A spring bearing, tending to centre the spindle, was not alone sufficient. The india-rubber ring possessed a small amount of viscosity as well as resilience; its elasticity was equivalent to a spring pressing the axis into the centre from all sides, and thereby helping to steady its running. But any such spring had of course a certain amount of reciprocity in relation to the vibrations of the spindle; and a spring which he had tried had been found not to answer, because at certain speeds, at which the rate of rotation of the spindle was a multiple of the period of vibration of the spring, so great a vibration had been set up that it caused the blades to foul. To prevent this a considerable amount of frictional resistance was required, which had now been obtained with the washers. Another point, which was perhaps rather interesting from a scientific point of view, was that the body of the steel spindle itself of say 4 inches 
diameter, if it were running in fixed bearings at 10,000 revolutions per minute, would be very apt to "whip" or bend; the whole spindle would bend bodily, and its mass revolving eccentrically about the fixed bearings would produce intense pressure on the bearings, and would cause them to heat. The washer bearing combined the resilience due to the spindle itself with the frictional resistance of the washers to any motion. The same principle held good here as with the gyroscope, that when pressure was applied in one direction it produced a motion at right angles, and so brought the spindle back to its central position, involving a minimum of motion to the washers.

With regard to abrasion and knocking, the film of oil always surrounding the bearing entirely prevented abrasion. At certain speeds these machines ran a great deal more quietly than at others; it was found that below 8,000 revolutions per minute the noise was much diminished; it was not observed nearly so much, and in all except the very small sizes this was fixed as the limit of speed. The mechines at Lincoln's Inn, mentioned by Professor Forbes (page 506), were running at a little over 9,000, between 9,000 and 9,500 revolutions per minute; and for that reason they caused more noise than usual.

As to the comparative loss of efficiency in the compound turbine with a reduction in the steam pressure or in the speed (page 508), he was not aware what was the duty to expect from compound engines under varying loads, or what their consumption was at half loads; but from a theoretical point of view he should expect the same comparative average efficiency from the compound turbine as from compound engines. If the maximum efficiency was identical in the two cases, the average efficiency would be about the same, or perhaps rather better in the turbine because it had so much less friction; the frictional resistanc's of the spindle bearings did not amount to more than 2 per cent. of the power developed. The areas of the passage-ways between the blades were of course fixed, increasing in size in the successive turbines; they corresponded directly with the areas of the cylinders in a compound engine, and he thought therefore the average efficiency should be about the same. 
(The Hon. Charles A. Parsons.)

The idea cf continuons oiling had probably been borrowed, as mentioned by Mr. Paget (page 503), from the papers read at this Institution; but as he had adopted the principle in the high-speed engines he had designed and made eight years ago, he could not give a definite answer on this point. He had at that time proved the great reduction of friction which resulted from continuous lubrication. He had found practically that, in such a small bearing running at so high a speed, the heat generated in the bearing was more than could be carried away by radiation, and that the flow of oil over the surface was a great preventive of local heating and of consequent seizing in the bearing. It would run for a short time without eontinuons lubrication; but the bearings were sure to get into bad order, and they would be cortain to seize eventually.

Breakages of the blades, about which Professor Forbes had enquired (page 506), had in a few individual cases been a source of trouble. The blades had in some cases been made too high in proportion to their breadth, and rather weak. This had now been remedied, and he thought there would be no more trouble with them. The larger turbines of 50 horse-power ran at about 6,500 revolutions per minute, and at that speed the velocity of the blades was about the theoretical velocity for best efficiency. As with the water turbine, there were certain rather wide limits between which a high efficiency was obtained, differing little from the maximum efficiency; the theoretical velocity of the blades for best efficiency was about 60 or 70 per cent. of the velocity of the steam at its outfiow from the guide blades. The principal loss in the steam turbine was due to leakage, which he hoped to diminish greatly by better workmanship and other mcans.

In reply to Mr. Richmond's enquiry (page 507), the greatest number of lamps lighted by any one of the turbo-electric generators had been about 550.

He was greatly indebted to Mr. Head for his observations (pages 510-11), which were very suggestive indeed; and he hoped that some of them might be realized. In regard to aerial navigation and the application of petroloum to work the compound turbine, he would say that the matter was one of great interest. 
A valuable piece of information about the furmation of ice had been contributed by Mr. Scott-Moncrieff (page 512). He had not himself been aware previously that ice was not formed so much when the air was properly expanded continuously. It seemed difficult to account for such a resilt, and he should have thought that, the more work was taken out of the air, the more ice would be formed : if the temperature was more lowered by expansion in the engine, it seemed natural to expect that more of the water which was held in suspension in the air would be formed into ice. The statement now made be hoped would be found to hold good, because it was a great disadvantage to have to heat the air, even though it did give a slight increase of volume and efficiency. The compound turbine ought to be a very good motor indeed for working with compressed air, especially in connection with the distribution of power by compressed air in the manner indicated by Mr. Sturgeon in the previous discussion (pages 487-8).

On board the "City of Berlin" (page 505), which was the first large ship that had been lit with electric lights by this means, there were 420 glow lamps, and two generators, each carable of maintaining the whole number of lamps. A large number of the turbos were now at work, amounting in all he thought to a little over 3,000 electrical horse-power.

In regard to the application of the turbo-electric generator to central station lighting, he could fully endorse the remarks made by Professor Forbes (page 507): the dynamo with its very high efficiency and high speed of rotation gave the most suitable number of reversals, namely 16,000 per minute. The turbo motor, possessing fair economy in the smaller sizes and high economy in the larger, would when fully developed as a condensing engine possess this quality in a more remarkable degree than had perbaps ever been anticipated in relation to any steam engine.

The Charrman said this machine was no doubt a remerkalle development from the original rotary engine referred to by Mr. Head as having been made by an ancient philosopher, in which the steam was wastefully discharged direct from the revolving boiler into the 
(Mr. Charles Cochrane.)

atmosphere, and simply by its reaction turned the apparatus round. Passing on from that merely scientific toy, there followed the windmill with its extravagant waste of air blowing through its vanes, doing very little efficient work compared with the volume of air that passed through it. And now came the wonderful apparatus described by the author, by which almost the duty of a triple-expansion engine was done, or seemed likely to be done; for while the steam was at present expanded down to atmospherie pressure only, the hope was expressed that condensing would be brought to bear upon it. Already at the Newcastle exhibition last year the clearance he understood had been reduced from 1-32nd of an inch to only half as much or 0.015 inch, and by that little alteration alone 50 per cent. of the leakage had been saved. Therefore he could not help thinking that, when the work was put together in the improved way which the author had now indicated, the bulk of the remaining leakage would be further got rid of ; and by-and-bye a perfect machine would be produced of a kind which hitherto had not been in general operation, although there had been some rough and rude examples in the past. The Members he was sure wonld gladly join him in according a hearty vote of thanks to Mr. Parsons for his excellent paper.

Professor Ryar wrote that he regarded the compound steam turbine as a novel and admirable invention, and a special boon to electrical engineers. The high speed necessary for efficiency in the turbine was eminently suitable for the dynamo also, because it permitted diminution in the size of the armature and consequently in its reactive influence. The compound turbine completely surmounted the difficulty of varying temperature in the cylinder, because a permanent distribution of heat was attained; and owing to conduction the steam found itself for the most part in contact with metal which must be hotter than itself. Fluid friction 
was referred to in page 483 , and it would appear to observers as if this might amount to something considerable. It was an important consideration however that, if one of these engines were adequately jucketed, the heat developed by the friction would for the most part be returned to the steam and therefore not be lost. It would be very interesting if the author could furnish a record of the rate at which heat was lost, under the circumstances, firstly of the turbine containing steam at rest, and secondly of steam passing through it at the usual speed. The size and shape of the machine would readily permit of such measurements.

Ehingineers and students of physical science in general would be greatly indebted to the author if he would furnish the results of some of the very many experiments which he had conducted in connection with this subject. The information given in the paper on the methods of testing was sufficient to stimulate curiosity without exactly satisfying it. In seversl cases the terse and significant language used by the author might have been amplified with advantage. In the paragraph about the efficiency of the dynamo (pages 484-5), where it was said that the losses had been ascertained by "observing the change of steam pressure required to maintain the speed constant," did these words imply a series of observations with different loads at constant speed? And if so, the tests being presumably meant to take place under practical conditions, was it to be inferred that in actual practice it was thought fit to vary the steam pressure with the load, rather than to alter the speed? No doubt many would be glad to learn also whether the commercial efficiency of the dynamo, which was recorded as 95 per cent., had been ascertained by independent measurement, or inferentially by estimating the aggregate losses previously referred to.

The triple-expansion analogy hinted at in page 483 was surely an accidental resemblance merely, and therefore delusive as an analogy. A conspicuous merit of the compound turbine was that it enabled continuous expansion of the steam to take place. Theoretically the machine should be conical in form, tapering gradually outwards from the apex where the steam entered. If the exigencies of practical construction necessitated breaks here and there, forming a stepped 
(Professor Ryan.)

arrangement, the machine should not be characterised by what was after all a defect. In the rcciprocating triple-expansion engine the successive cylinders were not concessions to convenience of manufacture, but were means whereby to diminish initial strains and ranges of temperature, and so to obtain specifie advantage. The resemblance in form, he submitted, ought not to count for much. 


\section{COMPOUND STEAM TURBINE.}

Turbo-Electric Generator for 200 ampères at 80 volts, 25 H.P.

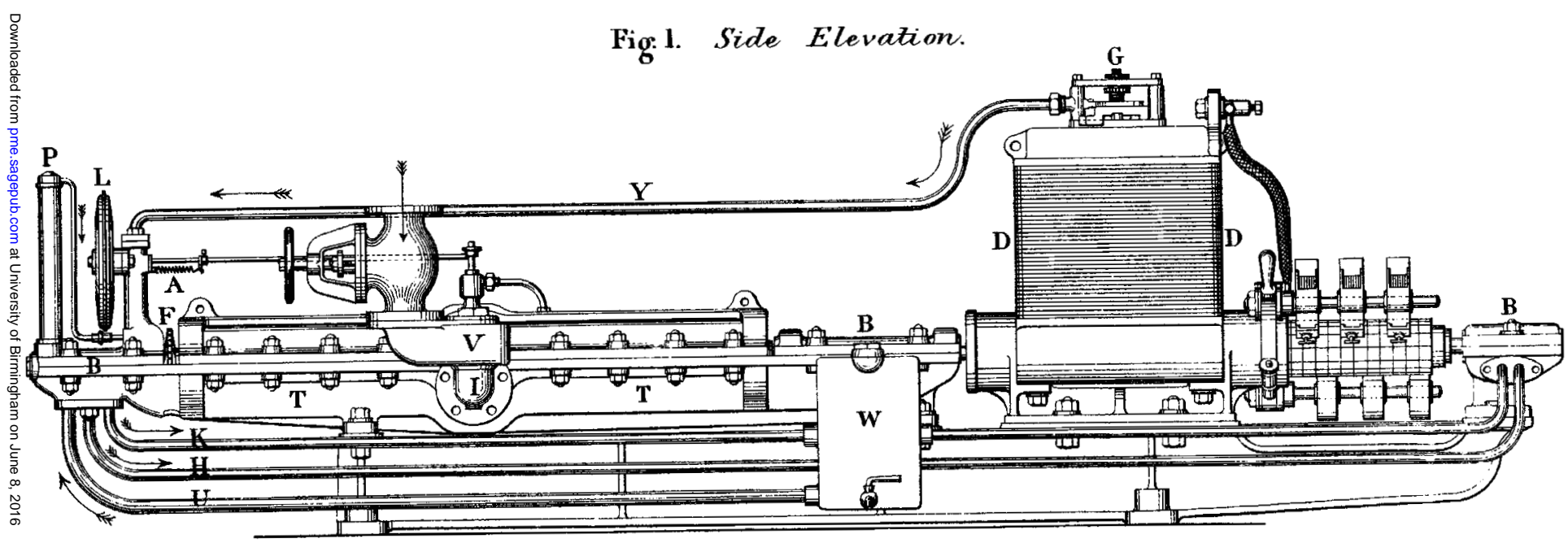

Fig: 1. Side Elevation. 


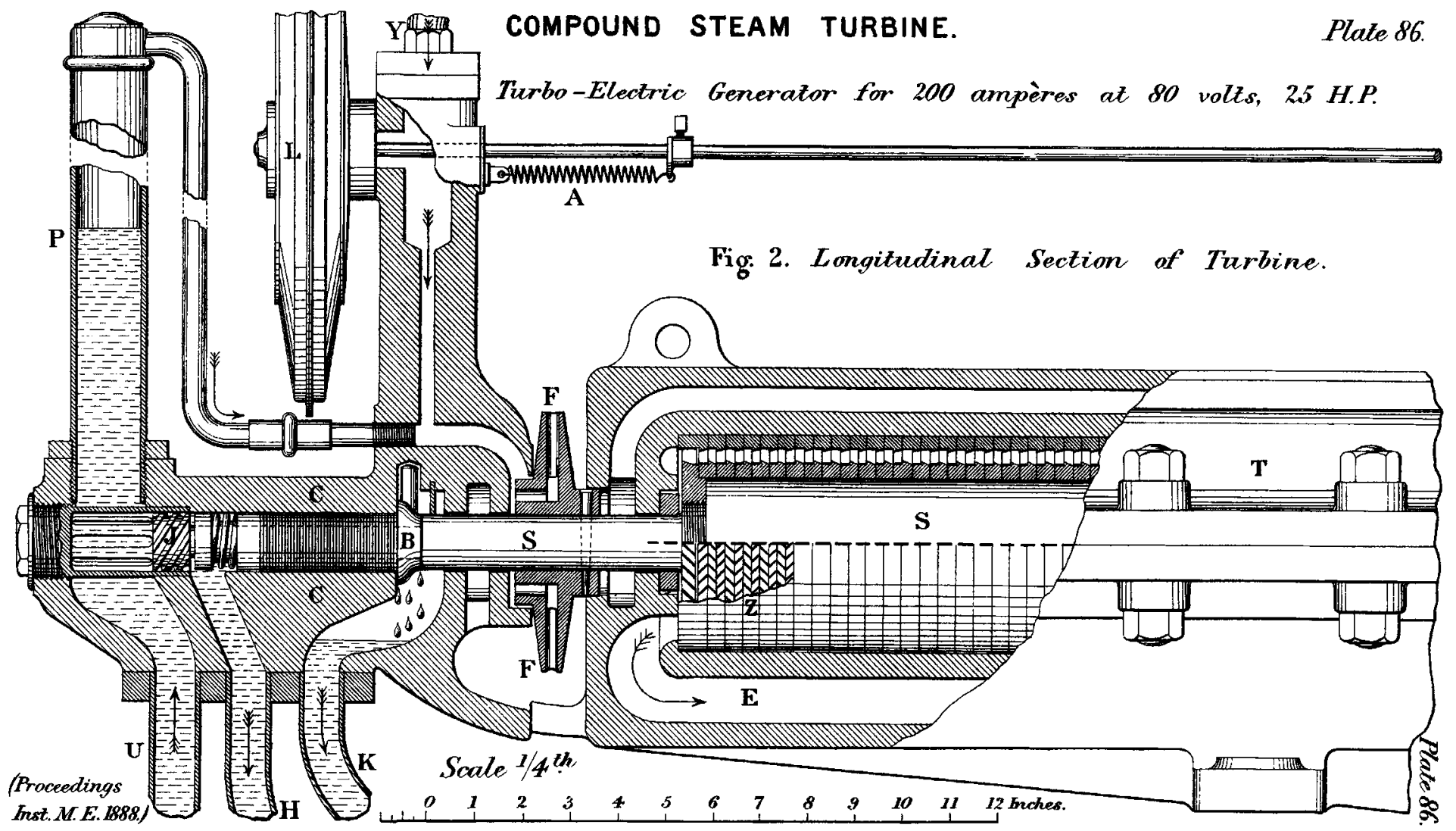




\section{COMPOUND STEAM TURBINE.}

Electrical Control Governor.

Fig. 5. Winding of Armature Scale $1 / 4^{\text {th }}$

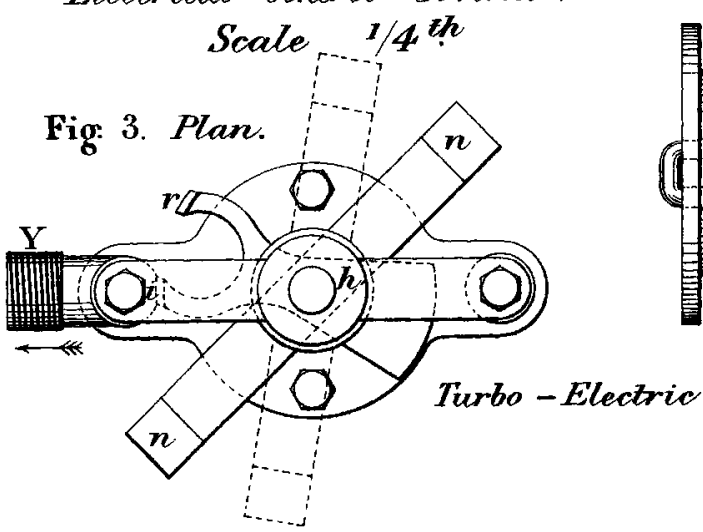

Fig: 4. Side Elevation.

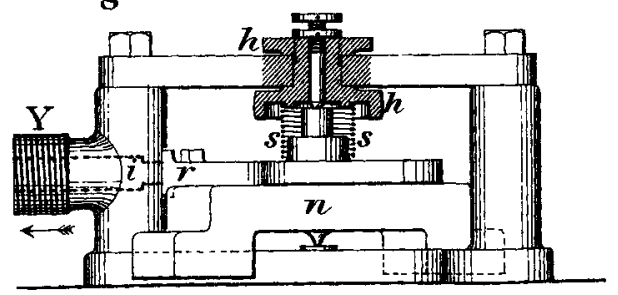

(Proceedings Thst. M.E. 2888.) Scale 1/4 th
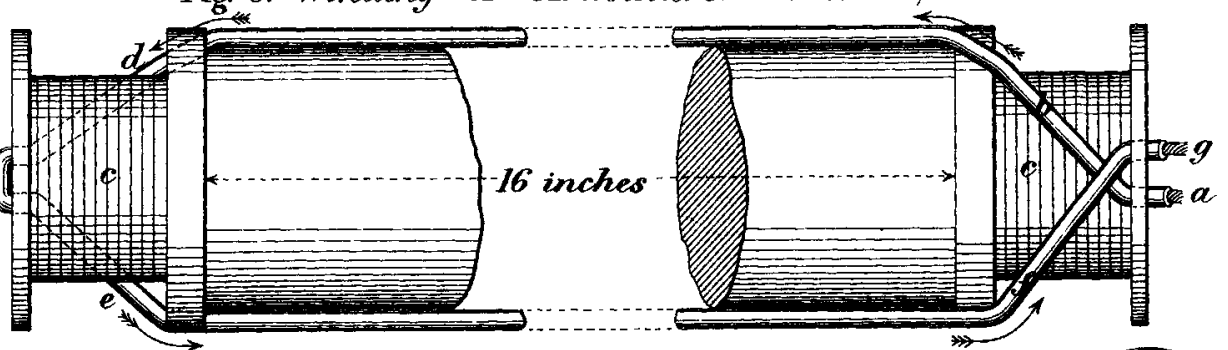

Generator for 200 ampères at 80 volts, 25 H.P.

Fig: 6. Longitudinal Section of Bearing. Full size.

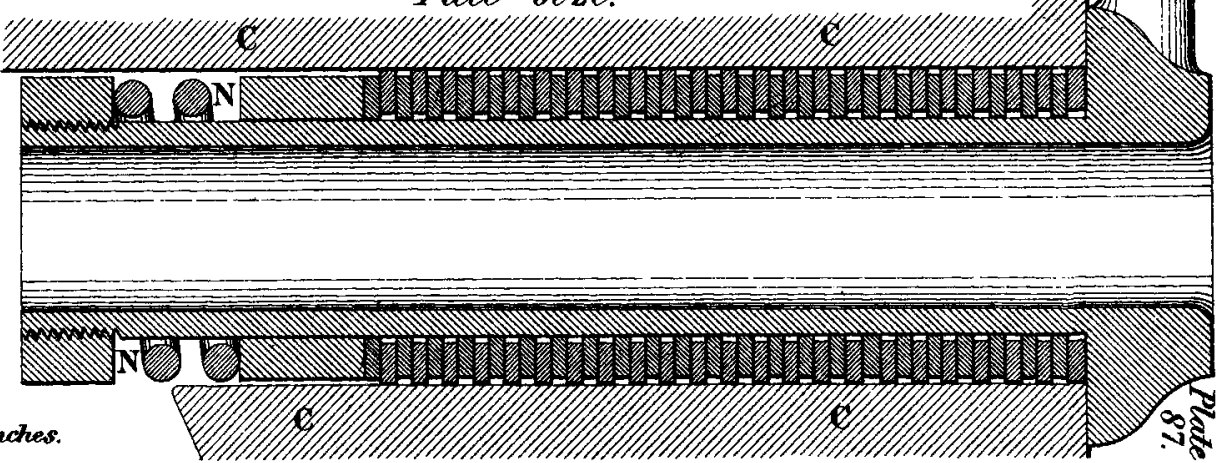


Turbo-Electric Generator for 400 ampères at 80 volts, $50 \mathrm{H} . \mathrm{P}$

Fig. 7. Side Elevation.

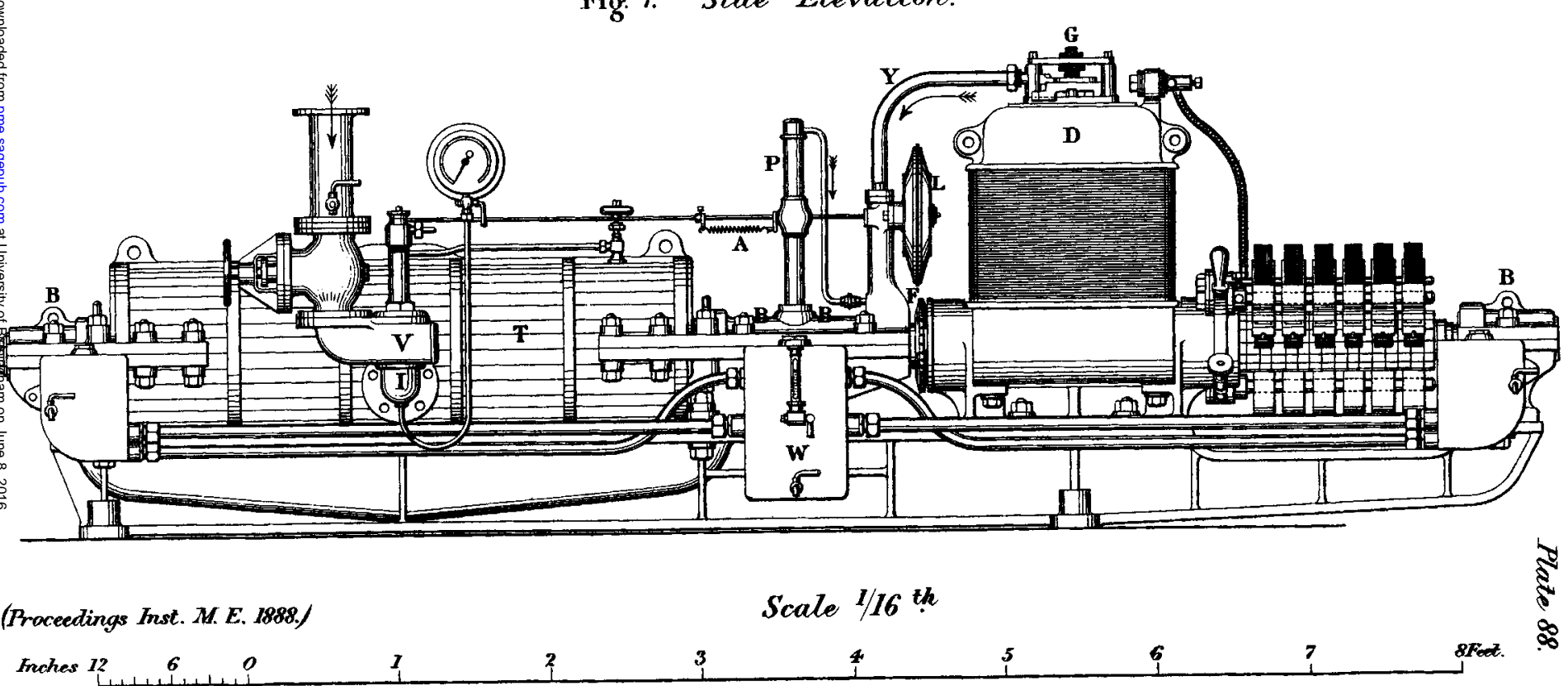




\section{COMPOUND STEAM TURBINE.}

Turbo-Electric Generator for 400 ampieres at 80 volts, 50 H.P.

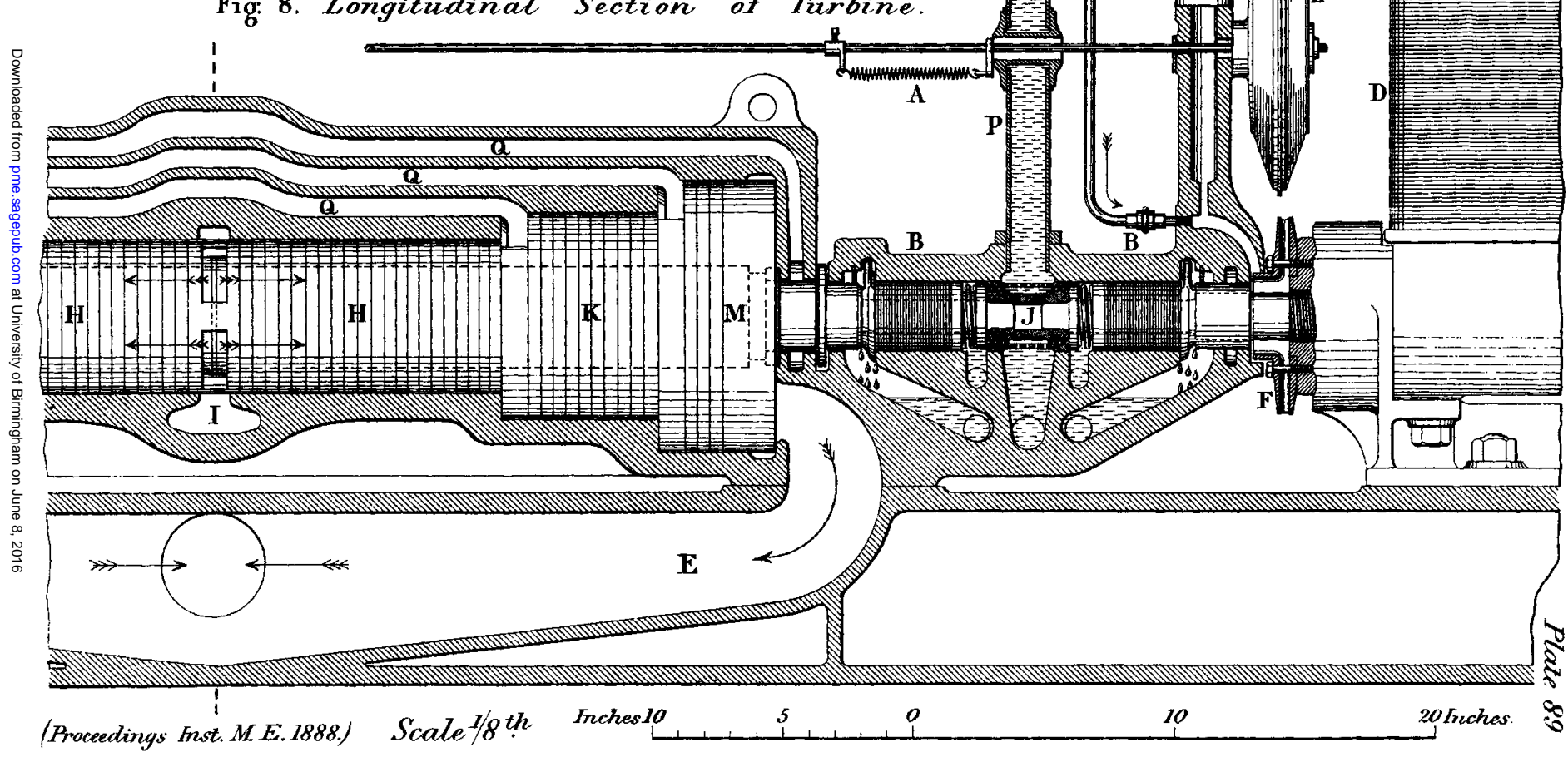




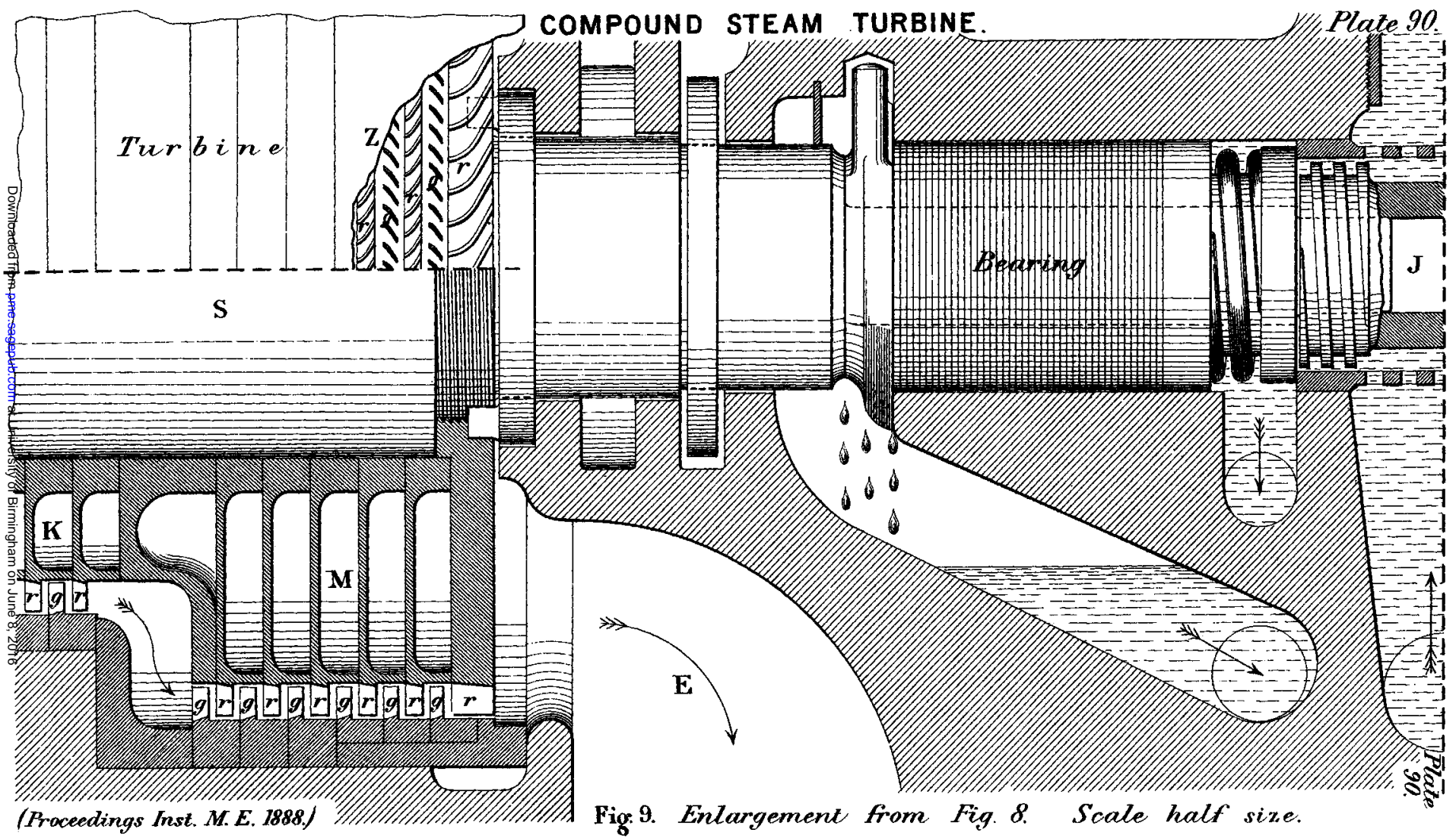

